psychiatry, presumably this relates to the nature of the posts for which that College is training its juniors.

It is essential in our reflection on the Chief Medical Officer's report that we bear in mind the requirement to train most juniors in our specialities for consultant work in the National Health Service.

F. CALDICOTT, President, Royal College of Psychiatrists

\section{Election to Fellowship}

Sir: While looking at the list of new Fellows (Psychiatric Bulletin, April 1994, 18, 253), it occurred to me that it may be useful for prospective applicants for fellowship to know the proportion of applicants to fellowship elected by the Court of Electors.

Would the College be prepared to disclose and publish this information as in membership examination results, e.g. "Out of $x$ number of applicants to the fellowship, $y$ number of applicants were approved by the Court of Electors".

ANIL KUMAR, Calderstones NHS Trust, Whalley, Clitheroe BB7 9PE

Sir: Dr Kumar's suggestion is very interesting and I will certainly take this to the next meeting of the Court of Electors who should have the first opportunity to discuss this.

VANEssa CAMERon, The Secretary, Royal College of Psychiatrists

\section{Post marketing surveillance studies}

Sir: The Research Committee statement on post marketing surveillance studies (PMS) (Psychiatric Bulletin, February 1994, 18, 115-1 16) contains much valuable information. It is unfortunate, however, that the committee bases its review on the 1988 PMS guideline which was superseded in 1993. The new 1993 guideline incorporates a number of significant additional clarifications and requirements.

(a) The terminology describing such studies has been clarified. Studies designed primarily to collect safety information, in which medication is prescribed according to data sheet indications (or studies which by their size alone add significantly to the safety database) are now called Safety Assessment of Marketed Medicine studies (SAMM). By contrast, trials involving marketed medicines having other primary objectives (e.g. blinded comparator studies or trials in new indications) are now called phase IV studies (phase $V$ in the Bulletin article). Separate guidelines have been published for the conduct of phase IV studies. Although a single study might meet criteria for both SAMM and phase IV definitions (and must then meet the conditions laid down in both guidelines), the terms are not synonymous as is suggested in the Bulletin articles.

(b) In future, the Medicines Control Agency (MCA) will review and expects to be able to comment on all aspects of SAMM study design. Liaison between sponsor company and the MCA will also cover initial communications between the company and medical practitioners. By this process the scientific rigour of the protocol and the nature of the agreement between sponsor and investigator will be open to the scrutiny of the regulatory body.

(c) The company is required to update the MCA on the progress of the study every six months. A final report must be submitted to the regulatory authority within three months of study completion. It is also expected that SAMM study results will be published in the scientific literature.

(d) The sponsor company is expected to have a rigorous process in place for the prompt collection and reporting to the MCA of appropriate adverse events (within 15 days for serious suspected adverse reactions, at study completion for minor reactions and other events).

The recent update is clearly aimed further to ensure both the scientific quality and rigorous conduct of safety studies involving newly marketed medicines. Copies are available from the Association of the British Pharmaceutical Industry (ABPI), 12 Whitehall, London SW1A 2DY.

Recent reports of blood dyscrasias associated with the use of novel antipsychotic drugs have highlighted the importance of SAMM in psychiatry. Debate surrounding this issue has been hindered by a lack of reliable data for older agents (Kerwin, 1993). Safety studies of novel psychotropic drugs will be important in the future. While the past conduct of such studies is rightly open to criticism, it will be important that practitioners have confidence in a future system which encourages safety assessment carried out in a proper scientific context. Familiarity with the additional safeguards incorporated into the new guidelines should be part of the confidencebuilding process.

KERWIN, R. (1993) Adverse reaction reporting and new antipsychotics (1993) Lancet, 342, 1440.

A.J. WooD, Lilly Research Centre Ltd., Erl Wood Manor, Sunninghill Road, Windlesham, Surrey GU20 6PH 